\title{
Association of rs10830963 MTNR1B and rs841853 SLC2A1 Polymorphism with Obesity on Type 2 Diabetes Patients: An Overview of Melatonin Receptor and Transporter
}

\author{
Yanuarita Tursinawati ${ }^{1, *}$ Arum Kartikadewi ${ }^{1}$, Ari Yuniastuti ${ }^{2}$, R Susanti ${ }^{2}$ \\ ${ }^{1}$ Faculty of Medicine, Universitas Muhammadiyah, Semarang, Jl. Kedungmundu No.18, Semarang 50273, Indonesia \\ ${ }^{2}$ Faculty of Mathematics and Natural Sciences, Universitas Negeri Semarang, Sekaran, Gunung Pati, Semarang 50229, Indonesia \\ *Corresponding author. E-mail: yanuarita_tursina@unimus.ac.id
}

Received date: Dec 30, 2020; Revised date: Mar 1, 2021; Accepted date: Mar 4, 2021

\section{Abstract}

B ACKGROUND: One of the hormones that plays a role in glucose metabolism of Type 2 Diabetes Mellitus (T2DM) is melatonin. Its genetic variation is believed to play a significant role in the pathophysiology of obese and non-obese T2DM. The role of MTNR1B (melatonin receptor coding gene) and SLC2A1 (Glucose transporter 1/GLUT 1 transporter coding gene) on the risk of obese and non-obese T2DM patients is controversial. This study aims to analyze the association between the rs 10830963 MTNR1B and rs841853 SLC2A1 polymorphism to the risk of Javanese obese T2DM.

METHODS: This was a cross-sectional study that involved 107 Javanese T2DM patients from primary heath care in Semarang. Furthermore, obese T2DM was defined by a body mass index (BMI) more than $25 \mathrm{~kg} / \mathrm{m}^{2}$. The genetic variations examined were rs10830963 MTNR1B and rs841853 SLC2A1 polymorphism by PCR-RFLP methods. Blood biochemistry parameters were also examined. Allele and genotype frequencies of rs10830963 MTNR1B and rs841853 SLC2A1 polymorphisms were analyzed using the $\mathrm{x}^{2}$ test with $p \leq 0.05$ and $95 \% \mathrm{CI}$.

RESULTS: There was a significant association between rs10830963 MTNR1B polymorphisms in obese and nonobese T2DM ( $p=0.044)$ and the CG genotype increased the risk of obese T2DM. Furthermore, the allele and genotype frequency of rs841853 SLC2A1 polymorphism in both group had no significant difference, with a $p=0.756$ and $p=0.802$, respectively. There was also no significant difference in the biochemical parameters' in both groups of the two genetic variants studied.

CONCLUSION: The rs10830963 MTNRIB polymorphism is associated with the risk of obesity in Javanese T2DM patients but not for the rs 841853 SLC2A1 polymorphism.

KEYWORDS: polymorphism, $M T N R 1 B, S L C 2 A 1$, obese, diabetes mellitus

Indones Biomed J. 2021; 13(2): 155-62

\section{Introduction}

Diabetes mellitus (DM), which is characterized by chronic hyperglycemia is a non communicable disease and becomes major problem in Indonesia. According to data, the total number of DM patients in 2019 was around 120,835 people, these include those that received health services by a standard of around 2,066 or $1.71 \%$.(1) Patients with type 2 DM (T2DM) experience abnormalities of blood glucose level homeostasis characterized by an increase of fasting plasma glucose (FPG).

Melatonin is one of the hormones that play a role in the metabolism of carbohydrate and regulates plasma glucose. Moreover, a decrease in the level of melatonin and an increase of insulin in Goto Kakizaki rats was found in T2DM.(2) The melatonin hormone works according to its target organ by binding to melatonin receptors, namely MT1, which is coded for MTNR1A and MT2 and encoded by MTNR1B gene. Furthermore, melatonin works across 
the plasma membrane in cells mediated by a transporter, namely Glucose transporter 1 (GLUT 1) coded by the SLC2A1 gene. $(3,4)$

Genome-wide Association Studies (GWAS) proved that there is a relationship between $M T N R 1 B$ polymorphisms and FPG, insulin secretion, and the T2DM incidence. $(5,6)$ This polymorphism occurs when $\mathrm{C}$ allele of the intron on of chromosome 11q21-q22 changes to G, which correlates with the risk of T2DM. The rs10830963 MTNR1B polymorphism was reported to be associated with increased FPG and T2DM in Caucasians, Chinese, Japanese, and Sri Lanka. $(7,8,9)$ Another genetic variation regarding the role of melatonin in DM is the rs841853 SLC2A1 polymorphism (XbaI G>T) which has been shown to double the risk of T2DM in Asia and Tunisian populations.(10)

The characteristics of T2DM patients vary widely. Classic T2DM patients usually have an obese condition. However, T2DM currently occurs in individuals with thin or normal body mass index (BMI). Lean T2DM patients show a faster loss of pancreatic beta-cell function than obese and therefore require earlier insulin treatment.(11,12) Studies in East Asia have shown that the onset of T2DM events is faster in individuals with lower BMI than in Caucasian. (11) Genetic involvement is believed to play a role in the T2DM pathogenesis of obese and non-obese patients. The genetic variations related to insulin secretion such as singlenucleotide polymorphism (SNP) TCF7L2 are at risk of normal (lean) T2DM BMI. However, those related to insulin sensitivity such as SNP fat mass obesity (FTO) are at risk of T2DM obesity.(13-15) SNP CDKN2BAS, CDKAL1 was associated with the risk of T2DM incidence in normal (lean) people.

Melatonin deficiency plays a role in obesity pathophysiology by regulating energy balance. It regulates energy intake, storage, and expenditure from adipose tissue, which determines a person's body weight. When the intake exceeds energy expenditure, it becomes overweight or obese. $(16,17)$ Obesity is a risk factor for DM incidence. A study involving obese subjects proved that GG genotype of polymorphism rs10830963 MTNR1B gene was associated with an increase in fasting glucose levels.(18) There was an association between XbaI restriction fragment length polymorphism (RFLP) GLUT 1 in T2DM obese women. This indicates that gene plays a role in the incidence of T2DM in obese people.(19)

The involvement of rs10830963 MTNR1B polymorphisms and rs841853 SLC2A1 in the risk of T2DM or obesity have been reported. However, there are no reports on the association of these genetic variations in obese and non-obese T2DM individuals. This study aims to analyze the relationship between $\mathrm{rs} 10830963$ MTNRIB and the rs841853 SLC2A1 polymorphism to the risk of obese and non-obese T2DM individuals of Javanese ethnicity, which is the largest ethnic group in Indonesia and the underlying clinical chemical parameters. The results will provide an overview of the contribution of genetic variation to the T2DM patients' heterogeneity based on BMI.

\section{Methods}

\section{Subject Collection}

This was an analytic observational study with a crosssectional approach involved 107 T2DM patients from 3 health care centers in Semarang. T2DM patients that met the inclusion criteria were consecutively sampled, including Javanese T2DM patients, aged 30-70 years and had signed informed consent. The exclusion criteria include a history of cardiovascular disorders such as stroke, heart failure, and acute myocardial infarction. Obese T2DM was defined by a BMI of more than $25 \mathrm{~kg} / \mathrm{m}^{2}$, according to the BMI classification of the Asia Pacific population. Ethical permission was obtained from the Ethics Commission of the Faculty of Medicine, the Muhammadiyah University of Semarang with Number 040/EC/FK/2019.

\section{Data Collection}

The weight and height of the samples were measured to calculate the BMI. Blood pressure was measured at rest and classifed into 5 classes, Normal: Systolic Blood Pressure (SBP) $<120 \mathrm{mmHg}$ or Diastolic Blood Pressure (DBP) $<80 \mathrm{mmHg}$; Prehypertension: SBP 120-139 mmHg or DBP 80-89 mmHg; Hypertension grrade 1: SBP 140$159 \mathrm{mmHg}$ or DBP $90-99 \mathrm{mmHg}$; Hypertension grade 2: $\mathrm{SBP} \geq 160 \mathrm{mmHg}$ or $\mathrm{DBP} \geq 100 \mathrm{mmHg}$, according to The Seventh Report of The Joint National Committee on Prevention, Detection, Evaluation, and Treatment of High Blood Presurre (JNC VII).(20) Venous samples were collected on ethylenediaminetetraacetic acid (EDTA) and plain tubes for the examination of gene polymorphisms and biochemical parameters, respectively, such as fasting blood sugar, cholesterol, triglycerides, high-density lipoprotein cholesterol (HDL-C), low-density lipoprotein cholesterol (LDL-C), Cholesterol/HDL ratio (Chol/HDL), urea, and creatinine. Microalbumin examination was carried out using the subject's urine sample. 


\section{Biochemical Profile Examination}

Respondents had fasted for 8 hours before collecting their venous blood to be examined for guanosine-diphosphatase (GDP) by an enzymatic method (GOD-PAP), ureum by Urease-glutamate dehydrogenase (GLDH), creatinine using the Jaffe, total cholesterol using CHOD-PAP, triglycerides using a GPO-PAP, HDL-C, and LDL-C by direct enzymatic method. Microalbumin was examined using respondents' urine samples with the immunoturbidimetric assay method and measured using a Cobas c311 autoanalyzer (Roche, Basel, Switzerland) at a wavelength of $340 \mathrm{~nm}$.

\section{Genotyping of MTNR1B Gene and SLC2A1 Polymorphism}

DNA was isolated from the blood using GeneJETTM Genomic DNA Purification Kit. Amplification of the MTNR1B gene was done using Primer forward 5'-ATG CTA AGA ATT CAC ACC AGC T-3 ', reverse 5'-CAC AGT GCA GAC TGT TTT CTA ATC. Polymerase chain reaction (PCR) with predenaturation of $95^{\circ} \mathrm{C}, 7$ minutes, 33 cycles: $95^{\circ} \mathrm{C}$ denaturation, 30 seconds, $60^{\circ} \mathrm{C}$ annealing, 30 seconds, $72^{\circ} \mathrm{C}$ elongation, 1 minute. The final extension was at $72^{\circ} \mathrm{C}$ for 3 minutes. RFLP method with PvuII enzyme was used to digest PCR product and visualized at $4 \%$ agarose gel. The electrophoresis results showed the $\mathrm{C}$ allele of $125 \mathrm{bp}$ and $\mathrm{G}$ at $105 \mathrm{bp}$ and $20 \mathrm{bp}$.
Amplification of $S L C 2 A 1$ was done using Primer forward 5'-TGC AAC CCA TGA GCT AAC AA-3 'and reverse 5'-GAA CCC AGC ACT CTG TAG CC -3'. PCR with predenaturation at $95^{\circ} \mathrm{C}, 5$ minutes, 33 cycles: $95^{\circ} \mathrm{C}$ denaturation, 30 seconds, $60^{\circ} \mathrm{C}$ annealing, 30 seconds, $72^{\circ} \mathrm{C}$ elongation, 1 minute. The final extension was at $72^{\circ} \mathrm{C}$ for 3 minutes. Then, PCR product was digested with $\mathrm{XbaI}$ enzyme and visualized at $2 \%$ agarose gel. Electrophoresis results showed the T allele of $305 \mathrm{bp}$ and $\mathrm{G}$ at $232 \mathrm{bp}$ and $73 \mathrm{bp}$.

\section{Data Analysis}

The data for the existence of rs10830963 MTNR1B and rs841853 SLC2A1 polymorphisms in the form of allele and genotype frequencies were analyzed by $\mathrm{x}^{2}$ test with $p<0.05$ and $\mathrm{CI}=95 \%$. The differences in the numerical characteristics of variables between groups were determined by the independent t-test.

\section{Results}

A total of 107 T2DM subjects, which consist of 45 obese and 62 non-obese were involved in the study. In the obese group, the majority of the sample was $\geq 60$ years old (46.7\%), female (82.2\%), uncontrolled blood sugar levels

Table 1. Characteristic data of T2DM subjects in obese and non-obese groups.

\begin{tabular}{lccc}
\hline & \multicolumn{2}{c}{$\mathbf{n ( \% )}$} & \\
\cline { 2 - 3 } & $\begin{array}{c}\text { Obese } \\
(\mathbf{n = 4 5 )}\end{array}$ & $\begin{array}{c}\text { Non-Obese } \\
(\mathbf{n}=\mathbf{6 2})\end{array}$ & $\boldsymbol{p}$-value* \\
\hline Age (year) & $1(2.2 \%)$ & $0(0 \%)$ & 0.660 \\
$30-34$ & $0(0 \%)$ & $0(0 \%)$ & \\
$35-39$ & $2(4.4 \%)$ & $1(1.6 \%)$ & \\
$40-44$ & $3(6.7 \%)$ & $4(6.5 \%)$ & \\
$45-49$ & $7(15.6 \%)$ & $7(11.3 \%)$ & \\
$50-54$ & $11(24.4 \%)$ & $21(33.9 \%)$ & \\
$55-59$ & $21(46.7 \%)$ & $29(46.8 \%)$ & \\
$\geq 60$ & & & \\
\hline Gender & $8(17.8 \%)$ & $17(27.4 \%)$ & \\
Male & $37(82.2 \%)$ & $45(72.6 \%)$ & \\
Female & & & \\
\hline Fasting Plasma Glucose Controlling & $29(64.4 \%)$ & $47(75.8 \%)$ & \\
Uncontrolled (<90 or $>130 \mathrm{mg} / \mathrm{dL})$ & $16(35.6 \%)$ & $15(24.2 \%)$ & \\
Controlled (90-130 mg/dL) & & & \\
\hline Hypertension & $3(6.7 \%)$ & $7(11.3 \%)$ & \\
Normal & $20(44.4 \%)$ & $28(45.2 \%)$ & \\
Prehypertension & $18(40.0 \%)$ & $18(29.0 \%$ & \\
Hypertension grade 1 & $4(8.9 \%)$ & $9(14.5 \%)$ & \\
Hypertension grade 2 & & & \\
\hline
\end{tabular}

* Tested with Chi square test, $p<0.05$ as significant result. 
Table 2. Biochemical profile of T2DM subjects in obese and non-obese.

\begin{tabular}{|c|c|c|c|c|c|}
\hline \multirow{2}{*}{ Biochemical Profile } & \multicolumn{2}{|c|}{ Obese } & \multicolumn{2}{|c|}{ Non-Obese } & \multirow{2}{*}{$p$-value* } \\
\hline & Mean \pm SD & Median (Min-Max) & Mean & Median (Min-Max) & \\
\hline FPG (mg/dL) & $155.02 \pm 9.94$ & $139(63-332)$ & $164.24 \pm 10.63$ & $141(60-418)$ & 0.752 \\
\hline $\mathrm{HbAlc}(\mathrm{mmol} / \mathrm{mol})$ & $7.82 \pm 0.27$ & $7.2(5.5-12.5)$ & $7.88 \pm 0.26$ & $7.45(4.9-15.4)$ & 0.847 \\
\hline Cholesterol (mg/dL) & $165.09 \pm 8.99$ & $160(41-266)$ & $194.08 \pm 5.99$ & $199.5(58-314)$ & $0.018^{*}$ \\
\hline Triglycerides (mg/dL) & $209.96 \pm 11.86$ & $194(78-402)$ & $202.34 \pm 21.78$ & $164(61-1340)$ & 0.060 \\
\hline $\mathrm{HDL}(\mathrm{mg} / \mathrm{dL})$ & $58.62 \pm 2.24$ & $58(33-97)$ & $61.65 \pm 2.32$ & $61(33-113)$ & 0.456 \\
\hline $\mathrm{LDL}(\mathrm{mg} / \mathrm{dL})$ & $201.31 \pm 8.47$ & $199(87-343)$ & $196.50 \pm 6.96$ & $204(88-311)$ & 0.786 \\
\hline Chol/HDL ratio & $4.91 \pm 0.21$ & $4.6(2.8-9.7)$ & $4.78 \pm 0.17$ & $4.6(2.6-9.2)$ & 0.645 \\
\hline Ureum (mg/dL) & $28.87 \pm 1.70$ & $25(15-61)$ & $30.40 \pm 1.48$ & $28(15-80)$ & 0.441 \\
\hline Creatinine (mg/dL) & $0.88 \pm 0.06$ & $0.76(0.44-2.49)$ & $0.96 \pm 0.63$ & $0.89(0.38-3.41)$ & 0.362 \\
\hline Microalbumin (mg/dL) & $241.89 \pm 54.93$ & $50.2(5-1582)$ & $281.27 \pm 132.03$ & $40.6(4.2-8087.2)$ & 0.202 \\
\hline
\end{tabular}

* Tested with Mann Whitney U test, $p<0.05$ as significant result.

(64.4\%), and prehypertension (44.4\%). Meanwhile, in the non-obese, the majority was $\geq 60$ years old $(46.8 \%)$, female (72.6\%), uncontrolled blood sugar levels $(75.8 \%)$, and prehypertension (45.2\%) as shown in Table 1.

Based on the comparison results of the biochemical profile in Table 2, there was a significant difference between the obese and non-obese groups in cholesterol levels with $p$-values of 0.018 . However,there was no significant differences in FPG, HbAlc, Triglycerides, HDL, LDL $\mathrm{Chol} / \mathrm{HDL}$ ratio, Ureum, creatinine, and microalbumin with $p>0.05$.

Table 3 shows that in both groups, the majority of respondents with rs10830963 MTNR1B polymorphism had the $\mathrm{C}$ allele which was the wild type allele. Furthermore,
$84.8 \%$ had CG genotype in the obese and $62.9 \%$ in the nonobese group. There was no significant difference between $\mathrm{C}$ and $\mathrm{G}$ alleles in both groups. However, the number of individuals with $\mathrm{CG}$ genotype was significantly higher than the CC in both groups with a $p$-value of 0.044 . There was also a significant relationship between rs10830963 MTNR1B polymorphisms with obese and non-obese T2DM types where the $C G$ genotype increased the risk of obesity. Meanwhile, in the rs841853 SLC2A1 polymorphism, most of the allele was $\mathrm{G}$ (wild type) and the most genotype was TT (45.2\%) in the non-obese group. Moreover, the obese group found the same number in the TG and TT genotypes. There were no significant differences in the allele frequency and genotype of rs841853 SLC2A1 polymorphism in the

Table 3. Allele distribution of rs10830963 MTNR1B and rs841853 SLC2A1 polymorphisms.

\begin{tabular}{|c|c|c|c|c|}
\hline & & \multicolumn{2}{|c|}{ n (\%) } & \multirow[b]{2}{*}{$p$-value* } \\
\hline & & $\begin{array}{c}\text { Obese } \\
(n=45)\end{array}$ & $\begin{array}{c}\text { Non-Obese } \\
(n=62)\end{array}$ & \\
\hline \multicolumn{5}{|c|}{ rs10830963 MTNR1B } \\
\hline \multirow[t]{2}{*}{ Allele } & $\mathrm{C}$ & $52(57.8 \%)$ & $83(66.9 \%)$ & 0.171 \\
\hline & $\mathrm{G}$ & $38(42.2 \%)$ & $41(33.1 \%)$ & \\
\hline \multirow[t]{3}{*}{ Genotype } & $\mathrm{CC}$ & $7(15.6 \%)$ & $22(35.5 \%)$ & $0.044 *$ \\
\hline & CG & $38(84.4 \%)$ & $39(62.9 \%)$ & \\
\hline & GG & $0(0 \%)$ & $1(1.6 \%)$ & \\
\hline \multicolumn{5}{|c|}{ rs841853 SLC2A1 } \\
\hline \multirow[t]{2}{*}{ Allele } & G & $54(60.0 \%)$ & $77(62.1 \%)$ & 0.756 \\
\hline & $\mathrm{T}$ & $36(40.0 \%)$ & $47(37.9 \%)$ & \\
\hline \multirow[t]{3}{*}{ Genotype } & GG & $9(20.0 \%)$ & $13(21.0 \%)$ & 0.802 \\
\hline & TG & $18(40.0 \%)$ & $21(33.9 \%)$ & \\
\hline & TT & $18(40.0 \%)$ & $28(45.2 \%)$ & \\
\hline
\end{tabular}

* Tested with Chi square test, $p<0.05$ as significant result. 


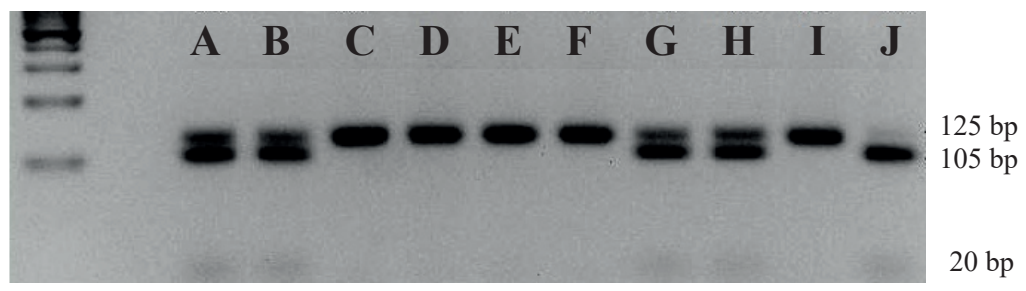

Figure 1. PCR-RFLP electrophoresis result of rs10830963 MTNR1B polymorphism. A, B, G, and H were CG heterozygotes; C, D, E, F, and I were CC homozygotes, while J was GG homozygotes.

obese and non-obese groups, with a $p$-value of 0.756 and 0.802 respectively.

The electrophoresis results of PCR-RFLP were shown in Figure 1 and Figure 2 for the MTNR1B and SLC2A1 gene, respectively. In Figure 1, it is seen that the letters A, B, G, and $\mathrm{H}$ had 125, 105 and $20 \mathrm{bp}$, respectively which were the CG (heterozygote) genotypes. C, D, E, F, and I had 125 bp (genotype CC) which were wild type alleles. J was GG homozygotes (105 and 20 bp). Meanwhile, in Figure 2, A, F, H, and I had 232 and 73 bp (genotype GG), B, C, E, G had 305,232 and $73 \mathrm{bp}$ (genotype TG) and D had 305 bp which was the TT genotype (homozygote risk allele T).

When comparing the biochemical profile results based on genotype on rs10830963 MTNR1B polymorphism between the obese and non-obese groups, it was found that there was no significant difference in biochemical parameters. However, there were higher but insignificant levels in the $\mathrm{CG}+\mathrm{GG}$ genotype for $\mathrm{FPG}, \mathrm{HbA1c}$, Cholesterol, Chol/HDL ratio, ureum, and microalbumin in the obese group. Likewise, with the non-obese group, levels of FPG, HbAlc, Cholesterol, HDL-C, LDL-C, ureum, creatinine, and microalbumin were higher in the $\mathrm{CG}+\mathrm{GG}$ genotype (Table 4).

Table 5 showed the comparation of biochemical profile parameters based on the genotype of the rs 841853 SLC2A1 polymorphism and shows that there was no significant difference between the values of the GG and TG + TT parameters in both groups.

\section{Discussion}

The clinical characteristics of T2DM patients may vary between obese and non-obese. This study analyzed the rs10830963 MTNR1B polymorphism in obese and nonobese T2DM individuals. The results indicate a significant relationship between rs10830963 MTNR1B polymorphisms in obese T2DM where the CG genotype increases the risk of T2DM obesity. Thus, this is contrary to research which identified the gene variations among T2DM obese and lean Han Chinese populations where this polymorphism was not associated with the risk of BMI in T2DM patients.(13) GG genotype, which has the risk of $\mathrm{G}$ allele is associated with a decreased beta-cell function (HOMA-B) and an increased insulin resistance (HOMA-IR) in adults.(18) Although there is a study showing that there is no correlation between HOMA-IR as a marker of insulin resistance and obesity.(21) Various genomic loci associated with the risk of predisposing the clinical characteristics of obese and non-obese T2DM have been identified. A study conducted in Medan, Indonesia proved that the genetic variations such as FTO rs9939609 is associated with the risk of Chinese children obese subjects. (22) The pathophysiology in obese patients is more towards insulin resistance, whereas in lean patients or non-obese it is caused by defective-insulin release or impaired insulin secretion. Meanwhile, the genetic variations that regulate insulin secretion (CDC123/CAMK1D, CDKAL1, TCF7L2,

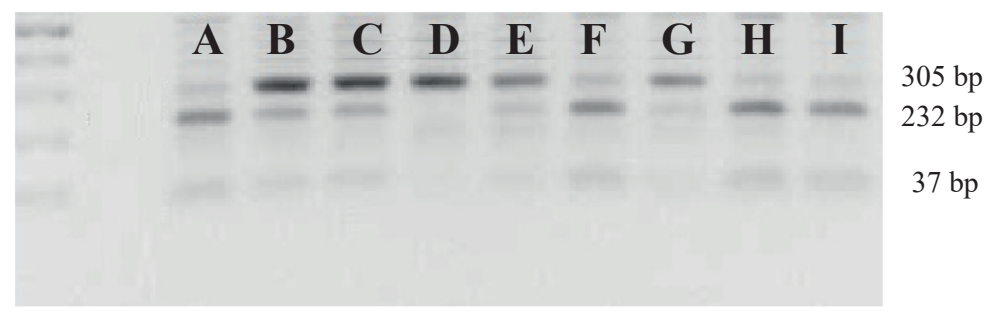

Figure 2. PCR-RFLP electrophoresis results of rs841853 SLC2A1 polymorphism. A, F, H, I are the GG genotypes; B, C, E, G are the TG genotypes and D was the TT genotypes (homozygote risk allele T). 
Table 4. The comparison of biochemical profile based on the genotype of rs10830963 MTNR1B polymorphism.

\begin{tabular}{|c|c|c|c|c|c|c|}
\hline \multirow[t]{2}{*}{ Biochemical Profile } & \multicolumn{2}{|c|}{$\begin{array}{c}\text { Mean } \pm \text { SD Obese } \\
(n=45)\end{array}$} & \multirow[t]{2}{*}{$p$-value } & \multicolumn{2}{|c|}{$\begin{array}{c}\text { Mean } \pm \text { SD Non-Obese } \\
(n=62)\end{array}$} & \multirow[t]{2}{*}{$p$-value } \\
\hline & $\mathrm{CC}$ & $(\mathbf{C G})+(\mathbf{G G})$ & & $\mathrm{CC}$ & $(\mathbf{C G})+(\mathbf{G G})$ & \\
\hline $\mathrm{FPG}(\mathrm{mg} / \mathrm{dL})$ & $123.43 \pm 16.49$ & $160.84 \pm 11.19$ & 0.167 & $146.86 \pm 15.03$ & $173.80 \pm 14.17$ & 0.219 \\
\hline $\mathrm{HbAlc}(\mathrm{mmol} / \mathrm{mol})$ & $6.94 \pm 0.47$ & $7.99 \pm 0.31$ & 0.177 & $7.29 \pm 0.35$ & $8.21 \pm 0.35$ & 0.053 \\
\hline Cholesterol (mg/dL) & $160.86 \pm 25.49$ & $165.87 \pm 9.71$ & 0.795 & $186.18 \pm 11.97$ & $198.43 \pm 6.59$ & 0.365 \\
\hline Triglycerides (mg/dL) & $211.43 \pm 20.62$ & $209.68 \pm 13.62$ & 0.725 & $209.68 \pm 54.77$ & $198.30 \pm 16.14$ & 0.151 \\
\hline $\mathrm{HDL}(\mathrm{mg} / \mathrm{dL})$ & $63.14 \pm 7.36$ & $57.79 \pm 2.30$ & 0.529 & $59.91 \pm 4.00$ & $62.60 \pm 2.87$ & 0.410 \\
\hline $\mathrm{LDL}(\mathrm{mg} / \mathrm{dL})$ & $224.57 \pm 29.48$ & $197.03 \pm 8.48$ & 0.415 & $189.18 \pm 11.34$ & $200.53 \pm 8.85$ & 0.431 \\
\hline Chol/HDL ratio & $4.74 \pm 0.54$ & $4.94 \pm 0.23$ & 0.702 & $4.54 \pm 0.29$ & $4.92 \pm 0.21$ & 0.131 \\
\hline Ureum (mg/dL) & $27.00 \pm 4.73$ & $29.21 \pm 1.84$ & 0.509 & $26.86 \pm 2.09$ & $32.35 \pm 1.94$ & 0.061 \\
\hline Creatinin $(\mathrm{mg} / \mathrm{dL})$ & $0.95 \pm 0.26$ & $0.87 \pm 0.06$ & 0.635 & $0.90 \pm 0.09$ & $0.99 \pm 0.08$ & 0.556 \\
\hline Microalbumin (mg/dL) & $97.61 \pm 46.98$ & $268.46 \pm 63.72$ & 0.347 & $112.96 \pm 47.11$ & $373.84 \pm 202.45$ & 0.332 \\
\hline
\end{tabular}

HHEX, CDKN2BAS, TCF7L2,KCNJ11) are associated with T2DM risk in lean or non-obese subjects.(14,23-25) Another study which examined the SNP-19 Calpain-10 (CAPN10) polymorphisms proved that this polymorphism is associated with Javanese ethnic vulnerability to T2DM. (26) Abnormalities in CAPN10 can reduce secretion in pancreatic cells which according to research plays a role in the pathophysiology of T2DM in non-obese patients.

The results showed that those with CG genotype were significantly higher than $\mathrm{CC}$ in both groups. Obesity and insulin sensitivity have a modulatory effect on the prediction of genetic susceptibility in the T2DM incidence. (27) A cohort study among obese respondents demonstrated that there was a significant relationship between SNP rs10830963 MTNR1B and the prevalence of prediabetes or Impaired Glucose Tolerance (IGT).(28) Therefore, it is presumed that this polymorphism is significantly associated with T2DM-induced obesity.
Other results of this study prove that there is no significant difference of allele and genotype frequency of rs841853 SLC2A1 polymorphism between 2 groups. The insignificant results in this study is due to ethnic differences, considering that the SLC2A1 polymorphism is also influenced by ethnicity.(29) Allele 1 of GLUT 1 is associated with T2DM especially in overweight/obese women.(19) There is an increase in proinflammatory in the obese, while proinflammatory increases the GLUT1 (SLC2A1) expression in macrophages. This increases glucose uptake as well as metabolism and ultimately causing hyperinflammatory conditions.(30) Other studies have also shown a correlation between inflammatory markers such as high sensitivity $\mathrm{C}$-reactive protein (hsCRP) in central obese elderly men.(31)

Other results also proved that the risk allele $G$ contained in the $\mathrm{CG}+\mathrm{GG}$ genotype increases the levels of FPG, HbAlc, cholesterol, ureum, and microalbumin in

Table 4. The comparison of biochemical profile based on the genotype of rs841853 SLC2A1 polymorphism.

\begin{tabular}{|c|c|c|c|c|c|c|}
\hline \multirow[t]{2}{*}{ Biochemical Profile } & \multicolumn{2}{|c|}{$\begin{array}{c}\text { Mean } \pm \text { SD Obese } \\
(n=45)\end{array}$} & \multirow[t]{2}{*}{$p$-value } & \multicolumn{2}{|c|}{$\begin{array}{c}\text { Mean } \pm \text { SD Non-Obese } \\
(n=62)\end{array}$} & \multirow[t]{2}{*}{$p$-value } \\
\hline & GG & $(\mathrm{TG})+(\mathrm{TT})$ & & GG & $(\mathrm{TG})+(\mathrm{TT})$ & \\
\hline FPG (mg/dl) & $159.22 \pm 14.86$ & $152.22 \pm 13.48$ & 0.677 & $161.39 \pm 17.55$ & $166.59 \pm 13.17$ & 0.515 \\
\hline $\mathrm{HbAlc}$ & $8.09 \pm 0.42$ & $7.65 \pm 0.37$ & 0.215 & $7.61 \pm 0.39$ & $8.11 \pm 0.36$ & 0.520 \\
\hline Cholesterol (mg/dl) & $174.50 \pm 12.42$ & $158.81 \pm 12.52$ & 0.292 & $194.14 \pm 8.88$ & $194.03 \pm 8.26$ & 0.832 \\
\hline Triglycerides (mg/dl) & $215.72 \pm 20.16$ & $206.11 \pm 14.77$ & 0.719 & $199.00 \pm 17.82$ & $211.68 \pm 37.13$ & 0.904 \\
\hline $\operatorname{HDL}(\mathrm{mg} / \mathrm{dl})$ & $56.28 \pm 3.41$ & $60.19 \pm 2.97$ & 0.501 & $61.54 \pm 3.57$ & $61.74 \pm 3.09$ & 0.944 \\
\hline $\mathrm{LDL}(\mathrm{mg} / \mathrm{dl})$ & $199.28 \pm 14.88$ & $202.67 \pm 10.28$ & 0.899 & $203.75 \pm 10.23$ & $190.53 \pm 9.51$ & 0.380 \\
\hline Chol/HDL ratio & $4.76 \pm 0.27$ & $5.02 \pm 0.30$ & 0.898 & $4.95 \pm 0.28$ & $4.64 \pm 0.22$ & 0.308 \\
\hline Ureum (mg/dl) & $26.61 \pm 2.18$ & $30.37 \pm 2.43$ & 0.313 & $32.82 \pm 2.57$ & $28.41 \pm 1.64$ & 0.183 \\
\hline Creatinin (mg/dl) & $0.76 \pm 0.06$ & $0.96 \pm 0.09$ & 0.211 & $1.00 \pm 0.11$ & $0.92 \pm 0.07$ & 0.529 \\
\hline Microalbumin (mg/dl) & $197.45 \pm 89.48$ & $271.511 \pm 70.25$ & 0.271 & $162.53 \pm 43.54$ & $379.06 \pm 238.41$ & 0.651 \\
\hline
\end{tabular}


both groups, although not significant. The risk allele G, which increases FPG is consistent with previous study. (18) In addition, the expression of the MTNR1B gene in pancreatic beta islet cells has a direct effect on regulating FPG levels. Therefore, when polymorphisms occur in this gene, it directly affects FPG. Furthermore, individuals at risk of allele $\mathrm{G}$ experience hepatic insulin resistance due to a decrease in suppression of hepatic glucose production during euglycemic hyperinsulinemia. This is also due to an increase in the hepatic glucose production rate, which increases gluconeogenesis.(8) In non-obese T2DM patients, there was also an increase in basal production of hepatic glucose, which resulted in an increase in FPG levels. In the obese group, cholesterol and LDL levels were higher in the allele $\mathrm{G}$ risk group. Other studies that analyze MTNR1B polymorphisms in relation to lipid profiles, stated that cholesteol and LDL have a relationship with the rs3781637 MTNR1B polymorphism. (32)

Furthermore, there is no significant difference in the biochemical parameters between GG and TG + TT of rs841853 SLC2A1 polymorphism. However, the values of FPG, HbAlc, triglycerides, HDL, and microalbumin are higher in the TG + TT group. A high microalbumin levels in T2DM patients indicate a complication of DM nephropathy. The diagnosis of DM nephropathy is carried out when the urinary albumin level is $>300 \mathrm{mg} / 24$ hours with or without an increase in serum creatinine $(>1.3 \mathrm{mg} /$ $\mathrm{dL})$. In the non-obese group, a mean microalbumin $>300$ $\mathrm{mg} / \mathrm{dL}$ was found, which indicates the risk of nephropathy. (33) Furthermore, several studies have shown a relationship between the rs841853 SLC2A1 polymorphism and the risk of DN which is marked by an increase in microalbumin.(34) TT haplotype was found in nephropathy patients as reported by previous study.(35) However, this is not proven by the results of this study.

\section{Conclusion}

There is a significant relationship between rs10830963 MTNR1B polymorphism in obese and non-obese T2DM, where the CG genotype increases the risk of obese T2DM. Furthermore, there is no differences in the allele and genotype frequency of rs841853 SLC2A1 polymorphism in the obese and non-obese groups. There is also no significant difference in the biochemical parameters in obese and non-obese groups on the two genetic variants studied. In addition, rs 10830963 MTNR1B polymorphism is associated with the risk of obesity in Javanese T2DM patients but not for the rs841853 SLC2A1 polymorphism.

\section{Acknowledgements}

The authors are grateful to the Central Laboratory of Diponegoro University Semarang (Cebior), the Laboratory of the Mathematics and Natural Sciences Faculty, CITO laboratory and the Public Health Center that helped with the data collection. The authors are also grateful to the Directorate of Research and Community Services, Directorate General of Research and Development, Ministry of Research, Technology, and Higher Education, under the scheme of Research on Inter-University Collaboration for funding this study.

\section{Authors Contribution}

YT, AK, AY and RS carried out the research; YT organized research data, performed data analysis, interpretation, wrote the manuscript and prepared final version for publication; AK performed data analysis and interpretation of data; AY and RS helped review the data analysis and reviewed the manuscript.

\section{References}

1. Kementrian Kesehatan RI. Profil Kesehatan Indonesia 2019. Jakarta: Kementrian Kesehatan RI; 2020.

2. Peschke E, Frese T, Chankiewitz E, Peschke D, Preiss U, Schneyer U, et al. Diabetic Goto Kakizaki rats as well as type 2 diabetic patients show a decreased diurnal serum melatonin level and an increased pancreatic melatonin-receptor status. J Pineal Res. 2006; 40: $135-43$.

3. Reiter RJ, Tan DX, Rosales-Corral S, Galano A, Jou MJ, AcunaCastroviejo D. Melatonin mitigates mitochondrial meltdown: Interactions with SIRT3. Int J Mol Sci. 2018; 19: 2-28.

4. Hevia D, González-Menéndez P, Quiros-González I, Miar A, Rodríguez-García A, Tan DX, et al. Melatonin uptake through glucose transporters: A new target for melatonin inhibition of cancer. J Pineal Res. 2015; 58: 234-50.

5. Prokopenko I, Langenberg C, Florez JC, Saxena R, Soranzo N, Thorleifsson $\mathrm{G}$, et al. Variants in the melatonin receptor $1 \mathrm{~B}$ gene (MTNR1B) influence fasting glucose levels. Nat Genet. 2010; 41: $77-81$

6. Takeuchi F, Katsuya T, Chakrewarthy S, Yamamoto K, Fujioka A, Serizawa M, et al. Common variants at the GCK, GCKR, G6PC2ABCB11 and MTNR1B loci are associated with fasting glucose in two Asian populations. Diabetologia. 2010; 53: 299-308.

7. Kwak SH, Jang HC, Park KS. Finding genetic risk factors of gestational diabetes. Genomics Inf. 2012; 10: 239-43.

8. Sparsø T, Bonnefond A, Andersson E, Bouatia-Naji N, Holmkvist $\mathrm{J}$, Wegner L, et al. G-allele of intronic rs10830963 in MTNR1B confers increased risk of impaired fasting glycemia and type 2 diabetes through an impaired glucose-stimulated insulin release: Studies involving 19,605 Europeans. Diabetes. 2009; 58: 1450-6. 
9. Song JY, Wang HJ, Ma J, Xu ZY, Hinney A, Hebebrand J, et al. Association of the rs10830963 polymorphism in MTNR1B with fasting glucose levels in Chinese children and adolescents. Obes Facts. 2011; 4: 197-203.

10. Du B, Liu S, Cui C, Wang S, Cui W. Association between glucose transporter 1 rs 841853 polymorphism and type 2 diabetes mellitus risk may be population specific. J Diabetes. 2013; 5: 291-9.

11. Ma RCW, Chan JCN. Type 2 diabetes in East Asians: Similarities and differences with populations in Europe and the United States. Ann NY Acad Sci. 2013; 1281: 64-91.

12. George AM, Jacob AG, Fogelfeld L. Lean diabetes mellitus: An emerging entity in the era of obesity. World J Diabetes. 2015; 6: 613-20.

13. Kong X, Xing X, Hong J, Zhang X, Yang W. Genetic variants associated with lean and obese type 2 diabetes in a Han Chinese population A case-control study. Medicine (Baltimore). 2016; 95: e3841. doi: 10.1097/MD.0000000000003841.

14. Timpson NJ, Lindgren CM, Weedon MN, Randall J, Ouwehand WH, Strachan DP, et al. Adiposity-related heterogeneity in patterns of type 2 diabetes susceptibility observed in genome-wide association data. Diabetes. 2009; 58: 505-10.

15. Boutsouris K, Poumpouridou N, Katsarou M, S, Gourzi TF, Tentolouris K, et al. Frequency distribution of TCF712, MTNR1B, CDKA11, SLC30A8 and FTO gene polymorphisms predisposing to type II diabetes mellitus and/or obesity in a greek population and their impact in personalized medicine. Arch Balk Med Union. 2016; 51: 157-63.

16. Cipolla-Neto J, Amaral FG, Afeche SC, Tan DX, Reiter RJ. Melatonin, energy metabolism, and obesity: A review. J Pineal Res. 2014; 56 : 371-81.

17. Szewczyk-Golec K, Rajewski P, Gackowski M, Mila-Kierzenkowska $\mathrm{C}$, Wesołowski R, Sutkowy P, et al. Melatonin supplementation lowers oxidative stress and regulates adipokines in obese patients on a calorie-restricted diet. Oxid Med Cell Longev. 2017; 2017: 8494107. doi: 10.1155/2017/8494107.

18. De Luis DA, Izaola O, Primo D, Aller R. Association of the rs10830963 polymorphism in MTNR1B with fasting glucose, serum adipokine levels and components of metabolic syndrome in adult obese subjects. Nutr Hosp. 2019; 36: 60-5.

19. Pontiroli AE, Capra F, Veglia F, Ferrari M, Xiang KS, Bell GI, et al. Genetic contribution of polymorphism of the GLUT1 and GLUT4 genes to the susceptibility to type 2 (non-insulin-dependent) diabetes mellitus in different populations. Acta Diabetol. 1996; 33: 193-7.

20. Chobanian AV, Bakris GL, Black HR, Cushman WC, Green LA, Izzo JL Jr, et al. Seventh report of the Joint National Committee on prevention, detection, evaluation, and treatment of high blood pressure. Hypertension. 2003; 42: 1206-52

21. Budiyati R, Lukito W, Wijaya A. Correlation between visfatin, insulin resistance (homeostasis model assesment of insulin resistance), inflammation (high sensitivity C-reactive protein) and HDL cholesterol concentration in individuals with visceral obesity. Indones Biomed J. 2010; 2: 61-5.

22. Lubis SM, Fattah M, Damanik HA, Batubara JRL. Association of fat mass and obesity-associated Gene (FTO) rs9939609 variant with early onset obesity among bataknese and Chinese children in Indonesia: A case-control study. Indones Biomed J. 2017; 9: 14752.

23. Cauchi S, Choquet H, Gutiérrez-Aguilar R, Capel F, Grau K, Proença $\mathrm{C}$, et al. Effects of TCF7L2 polymorphisms on obesity in European populations. Obesity. 2008; 16: 476-82.

24. Voight BF, Scott LJ, Steinthorsdottir V, Andrew P, Aulchenko YS, Thorleifsson G, et al. Twelve type 2 diabetes susceptibility loci identified through large-scale association analysis. Nat Genet. 2010; 42: 579-89.

25. Saxena R, Gianniny L, Burtt NP, Lyssenko V, Giuducci C, Sjögren $\mathrm{M}$, et al. Common single nucleotide polymorphisms in TCF7L2 are reproducibly associated with type 2 diabetes and reduce the insulin response to glucose in nondiabetic individuals. Diabetes. 2006; 55 2890-5.

26. Tursinawati Y, Hakim RF, Rohmani A, Kartikadewi A, Sandra F. CAPN10 SNP-19 is associated with susceptibility of type 2 diabetes mellitus: A Javanese case-control study. Indones Biomed J. 2020; 12: 109-14

27. Cauchi S, Nead KT, Choquet H, Horber F, Potoczna N, Balkau B, et $a l$. The genetic susceptibility to type 2 diabetes may be modulated by obesity status: Implications for association studies. BMC Med Genet. 2008; 9: 45. doi: 10.1186/1471-2350-9-45.

28. Linder K, Wagner R, Hatziagelaki E, Ketterer C, Heni M, Machicao $\mathrm{F}$, et al. Allele summation of diabetes risk genes predicts impaired glucose tolerance in female and obese individuals. PLoS One. 2012; 7: e38224. doi: 10.1371/journal.pone.0038224.

29. Amini S, Javanmardi M, Mokarizadeh A, Maroofi F, Jalali C, Azadi NA, et al. Association of HaeIII single nucleotide polymorphisms in the SLC2A1 gene with risk of diabetic nephropathy; evidence from Kurdish patients with type 2 diabetes mellitus. Qjm. 2016; 109: 399-404.

30. Freemerman AJ, Johnson AR, Sacks GN, Milner JJ, Kirk EL, Troester MA, et al. Metabolic reprogramming of macrophages: Glucose transporter 1 (GLUT1)-mediated glucose metabolism drives a proinflammatory phenotype. J Biol Chem. 2014; 289: 7884-96.

31. Triana R, Meiliana A, Halimah E, Wijaya A. Relationship between circulating protein $\mathrm{p} 53$ and high sensitivity $\mathrm{C}$-reactive protein in central obesity men with inflammaging. Indones Biomed J. 2019; 11: 59-62.

32. Ling $\mathrm{Y}, \mathrm{Li} \mathrm{X}, \mathrm{Gu} \mathrm{Q}, \mathrm{Chen} \mathrm{H}, \mathrm{Lu} \mathrm{D}, \mathrm{Gao} \mathrm{X}$. A common polymorphism rs3781637 in MTNR1B is associated with type 2 diabetes and lipids levels in Han Chinese individuals. Cardiovasc Diabetol. 2011; 10: 27.

33. Stefanidis I, Tziastoudi M, Tsironi EE, Dardiotis E, Tachmitzi SV, Fotiadou A, et al. The contribution of genetic variants of SLC2A1 gene in T2DM and T2DM-nephropathy: association study and meta-analysis. Ren Fail. 2018; 40: 561-76.

34. Stefanidis I, Kytoudis K, Papathanasiou AA, Zaragotas D, Melistas L, Kitsios GD, et al. XbaI GLUT1 gene polymorphism and the risk of type 2 diabetes with nephropathy. Dis Markers. 2009; 27: 29-35.

35. Rizvi S. Association of genetic variants with diabetic nephropathy. World J Diabetes. 2014; 5: 809-16. 